INTERNATIONAL DESIGN CONFERENCE - DESIGN 2018

https://doi.org/10.21278/idc.2018.0262

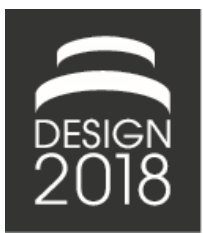

\title{
ENGAGING STUDENTS WHILE TEACHING DESIGN TOPICS ACROSS DIVERSE PROJECTS
}

\author{
S. Benjamin and J. Anderson
}

\begin{abstract}
We present an approach for integrating design topics in an undergraduate capstone design course. In addition to project work, students learn design topics, such as IP, robust design and DFMA. However, they struggle to integrate these into their project. To address this we require teams to explore connections between their project and a topic of our choosing and to present their findings to the class together with ideas for applying the topic to other projects. We find students engage better with these topics and are better able to articulate questions and concerns about what they are learning.
\end{abstract}

Keywords: capstone projects, design process, collaborative design, design education

\section{Introduction}

In an interdisciplinary project-based design course for upper-level undergraduate students, the time spent addressing advanced topics in design can frustrate the students' natural desire to focus only on their projects. The projects are varied, and the topics may not all be required for the immediate success of each project, or they may not be needed to the same degree or at the same point in each project. We present the topics in class using traditional methods, such as lectures, guided activities, and individual assignments. While students complete this work adequately, they later struggle to integrate the relevant topics into their projects, and they perceive the time and effort that they spend as a distraction. Paretti (2008) notes examples in which engineering students in a design class are "frustrated by activities that did not serve a clear purpose for their project and appeared mainly as course requirements," seeing these assignments as "counterproductive to the work they were attempting to accomplish." This is unfortunate, as this particular course is taken by engineering design majors, and it is the course where we emphasize the importance of these topics in design.

The literature on teaching capstone design frequently emphasizes the diversity, complexity, and intensity of capstone courses (Dutson et al., 1997; Miller and Summers, 2013). A number of researchers note both the necessity and difficulty of assessment when tracking students' mastery of the many elements of design (Davis et al., 2002; Shuman et al., 2005; Gruenther et al., 2009; Scott et al., 2013). Project-based design courses are both exceptional learning opportunities and challenging multifaceted projects in their own right, and demand teaching methods that are genuinely engaging and adaptive (Smith et al., 2005; Paretti, 2008) if students are to take full advantage of all these courses have to offer. To address this challenge, we have developed an approach that requires each student team to identify and share the connections between one of the topics and their project during a class session which we have named the Application Session. Each team delivers a presentation that

1. Teaches the class the key principles of that topic

2. Demonstrates how it applies specifically to their project

3. Identifies connections to other projects in the class 
Our experience suggests that the Application Session helps the teams to make progress on their projects while also providing a means to integrate advanced design topics into the curriculum. This is consistent with the findings of Grant et al. (2010) on the opportunities in design to introduce students to topics required for degree accreditation. We present here an overview of the course, details of the Application Session, and a discussion of the effectiveness of the session.

\section{Course overview and advanced topics}

In the interdisciplinary design projects course sequence, students work in small teams on open-ended design projects, each with a different external client. The goal in each case is to create a functional prototype that meets both client and user needs. The course is taught within the engineering school, but is open to third- through fifth-year students of any discipline who have completed a prerequisite introductory course on user-centered design. The class tends to be roughly two-thirds engineering students and one-third from other disciplines. The projects last approximately twenty weeks, spanning two academic quarters. The Application Session takes place in week five or six of the first quarter, and teams are expected to follow up with those topics in later presentations and in their final design report. The advanced topics included in the course were identified through benchmarking similar courses, considering popular textbooks (Dym, 2013; Ulrich and Eppinger, 2015), holding discussions with industry advisors, and reviewing what is covered in other courses within the engineering and design courses at our university. The selected topics and the teaching methods used are listed in Table 1 below.

Table 1. Advanced design topics

\begin{tabular}{|l|l|}
\hline Design topic & Teaching method \\
\hline Human factors engineering (HFE) & Interactive guest lecture \\
\hline Ethics and professional responsibility & Class discussion, individual reflection \\
\hline Intellectual property (IP) & Class activity or individual team consultation \\
\hline Design of experiments (DOE) and robust design & Interactive guest lecture \\
\hline Design for Manufacturing and Assembly (DFMA) & Interactive guest lecture \\
\hline Global, Societal, Environmental \& Economic (GSEE) issues & Class activity \\
\hline
\end{tabular}

While all of these topics are clearly important to design, their role in each team's project will vary greatly. The distinction drawn by Shuman et al. (2005) between "process skills" (e.g., ethical and professional responsibility) and "awareness skills" (e.g., understanding of the global or societal context of engineering decisions) is helpful here. Each team is expected to deploy ethical reasoning in their design process, and to gain deeper awareness of the particular issues their project raises. But each team's opportunities to do both will be unique.

For each of the topics listed above, there is an assigned reading followed by either an interactive guest lecture, or a class discussion or activity. Although the activities enable us to make some connections between the topics and the student projects, these connections are limited and do not appear to impact the students' ongoing project work. The Application Session provides an opportunity to make stronger connections and increase student engagement. This echoes Paretti's conclusions about the importance of connecting assignments to meaningful project needs. Paretti characterized situations where teams struggled against what they perceived as assignments not connected to their projects as lost learning opportunities (Paretti, 2008).

In addition to making stronger connections between the design topics and the projects, the Application Session also allows us to cover four diverse topics in a single class session, densely and at high speed, while retaining the students' attention. Done differently, students might question why these topics are all being covered in one day, but done as team presentations connected to their projects, it feels natural.

\section{Application session assignment}

For the Application Session, each team is assigned a topic that is well-aligned to their project, though it may not align as closely to other projects in the class. The assignment includes a general set of 
instructions on how to plan their presentation, as well as a series of prompts for their assigned topic. The general instructions are shown in Figure 1 below.

\section{Application Session}

There are two goals for this assignment:

1. To apply the design topics covered in the class to your project

2. To learn about design topics that may not be as applicable to your project, by seeing how they apply to one of the other projects in the class

Your team will teach the class about the application topic you have been assigned, using your project as a case study. You will have about 20 minutes to cover both the topic itself as well as how you have applied it (or will be applying it) to your project.

Content should include:

- The key principles of the topic in general (not connected to your project) -5 points

- An overview of the role this topic plays in your project -5 points

- Some specific actions you have taken/will take to integrate this topic in your project and include evidence-based criteria -10 points

- Relevant resources -2.5 points

- How you think it might connect to other projects in the class -2.5 points

You can prepare for the class using whatever medium or approach you wish. PowerPoint is fine but is not required. Whatever approach you select, be sure to review the relevant section in the Business Communication text and apply the appropriate principles to your class lesson.

Delivery should demonstrate:

- Application of at least one relevant principle from the Business Communication text - 5 points

\section{Figure 1. General assignment instructions}

The faculty assign the topics to the teams two weeks before the Application Session takes place. We discuss the key challenges each team is facing to identify topics important for them to explore in more depth. We then select a mix of topics that will both support the individual teams in making progress, as well as give the class increased exposure to topics they might not experience in their own projects.

The assigned topics tend to fall into three categories:

- Stakeholder needs and human factors - While every team needs to identify client, user, and other stakeholder needs, some projects have additional challenges that require going beyond the typical interviews, observations and research methods taught in an introductory level design course. For example, some users cannot articulate their needs or provide feedback on concepts due to physical or cognitive impairments, or the primary users may not be humans. There may also be conflicting needs or perspectives across the different stakeholder groups or even within the client organization itself. The team facing these challenges needs to consider alternate methods for gathering and communicating information.

- Engineering design and analysis - This category includes the Design for $\mathrm{X}$ topics, such as DFMA and DFE, as well as design of experiments, robust design, and tolerance analysis. The majority of the projects in the class will need to address at least one of these in some detail, though there is rarely time during the course for a team to explore multiple topics in depth.

- Societal issues - For many products and services, understanding how cultural and societal factors can impact the user experience is critical for successful adoption. Teams working on these projects need to think beyond ergonomics and ease-of-use, and strive to understand the broader context of use and the implications on potential designs.

The faculty also add a set of prompts to the assignment for each team. These prompts are customized to be specific to each project as opposed to general statements that could be applied to any project. This is to encourage teams to be thoughtful about the topics and to go into detail rather than treat the topics superficially. Some sample topics assignments and prompts are shown in Figure 2 below. 


\begin{tabular}{|c|c|}
\hline Project & Assignment topic and prompts \\
\hline $\begin{array}{l}\text { Fish Feeder } \\
\text { To create an } \\
\text { automatic feeder for } \\
\text { fish that promotes } \\
\text { natural behavior of } \\
\text { frequently looking } \\
\text { up for their food }\end{array}$ & $\begin{array}{l}\text { "Human" Factors } \\
\text { The Product Design and Development textbook and our guest lecturer both } \\
\text { highlight key elements of human factors. How do you translate these to be } \\
\text { relevant when the users are fish? } \\
\text { Since you will have limited access to testing with the actual fish, how can } \\
\text { you create a test that validates your concepts? Consider the following } \\
\text { points in your discussion. } \\
\text { - What is the use environment from the perspective of the fish? } \\
\text { - What are the characteristics of the concepts that you will need to } \\
\text { measure? In other words, what are you expecting the fish to notice and } \\
\text { respond to for each of your concepts? } \\
\text { - Without the presence of fish, how can you measure "noticeability" in } \\
\text { the given use environment? }\end{array}$ \\
\hline $\begin{array}{l}\text { Soccer Training } \\
\text { To give soccer } \\
\text { players more } \\
\text { measureable } \\
\text { training data }\end{array}$ & $\begin{array}{l}\text { Robust Design } \\
\text { Since the training product could be used in a variety of contexts and will } \\
\text { likely be subject to impact from a soccer ball, it will need to be robust to } \\
\text { these factors. Consider the journey of the product, including storage, } \\
\text { moving it to location, set up, use, take, down, etc. What are the different } \\
\text { conditions it will be subject to? Which of these are likely to be the most } \\
\text { challenging to address? How will you apply the principles of robust design } \\
\text { to address them? }\end{array}$ \\
\hline $\begin{array}{l}\text { Well Plate Assembly } \\
\text { To design a method } \\
\text { for pre-tensioning a } \\
\text { sheet of silicone as it } \\
\text { is bonded to a } 96 \\
\text { well plate body }\end{array}$ & $\begin{array}{l}\text { Tolerance Analysis \& DFMA } \\
\text { Your team is beginning to understand the role of tolerances in the design of } \\
\text { fixtures like the one used to assemble the well plate device. Consider how } \\
\text { this relates to design for manufacturing and assembly (DFMA). Although } \\
\text { the device is not currently intended to be mass manufactured, how can you } \\
\text { incorporate tolerance analysis and DFMA principles, focusing on the need } \\
\text { for precision (as opposed to DFMA principles used to reduce assembly costs } \\
\text { and time)? How does this also relate to usability of the fixture? }\end{array}$ \\
\hline $\begin{array}{l}\text { DIY Greenhouse } \\
\text { To design a low-cost } \\
\text { DIY greenhouse } \\
\text { structure that can be } \\
\text { assembled in } 2-3 \\
\text { days by farmers in } \\
\text { India, alone or with } \\
\text { the help of } 1-2 \\
\text { technicians }\end{array}$ & $\begin{array}{l}\text { DFMA } \\
\text { For your project, low cost and ease of assembly are both important design } \\
\text { factors. Although this is not going to be a high volume, mass-produced } \\
\text { product, the principles of Design for Manufacturing and Assembly (DFMA) } \\
\text { can still be applied to reduce the costs and make it easier for the user to } \\
\text { assemble with minimal assistance. How will you incorporate DFMA in your } \\
\text { process? Are some DFMA principles more important than others for your } \\
\text { design? How can you evaluate your design with respect to DFMA, and } \\
\text { benchmark it against other relevant products? }\end{array}$ \\
\hline $\begin{array}{l}\text { NU101 } \\
\text { To design and } \\
\text { develop an app that } \\
\text { helps NU students } \\
\text { manage their time } \\
\text { using visualizations } \\
\text { that support } \\
\text { priority-based } \\
\text { decision making }\end{array}$ & $\begin{array}{l}\text { Societal Factors } \\
\text { Relate societal factors to decision making process around } \\
\text { prioritization. Are there societal factors that influence how people assign } \\
\text { importance to their different activities? Think beyond obvious things like } \\
\text { logistic involved in using a calendar or application, and really consider the } \\
\text { things like societal expectations and pressures, the user's emotions, and } \\
\text { influence and pressures from family and friends. How do you learn about } \\
\text { these things in your design process and how do they impact your design } \\
\text { options? }\end{array}$ \\
\hline
\end{tabular}

Figure 2. Detailed assignment prompts 


\section{Results of application sessions}

The Application Sessions appear to be more effective than reading assignments or lectures alone. The need to create the Application Session presentation forces each team to get started on at least one of the design topics sooner in their process, and pay more attention to that topic throughout their process. We see the impact of this in their final reports.

We did a comparison between the 11 final reports from the 2016-2017 academic year (AY 2017), when we had implemented the application sessions, to the 10 reports from the previous year (AY 2016), which did not include these application sessions. For each report, we identified whether and how the design topics had been included as support of the overall design direction and decisions, and categorized the inclusion as follows:

- Central to the argument for the design

- Providing minor support for the design

- Mentioned in orphaned statements, not connected to the design argument

- Not mentioned

We also noted whether we expected the team to include that topic as part of the design report, as well as whether they had covered that topic in their Application Session (for the teams in the 2016-2017 academic year).

Although the sample size is small, there was a noticeable increase in the number of reports that included the design topics as either central or minor support. This can be seen in Figure 3, which shows a comparison of the two years, looking at reports where we expected the students to address particular design topics. There were no instances where a team included the topic unexpectedly.

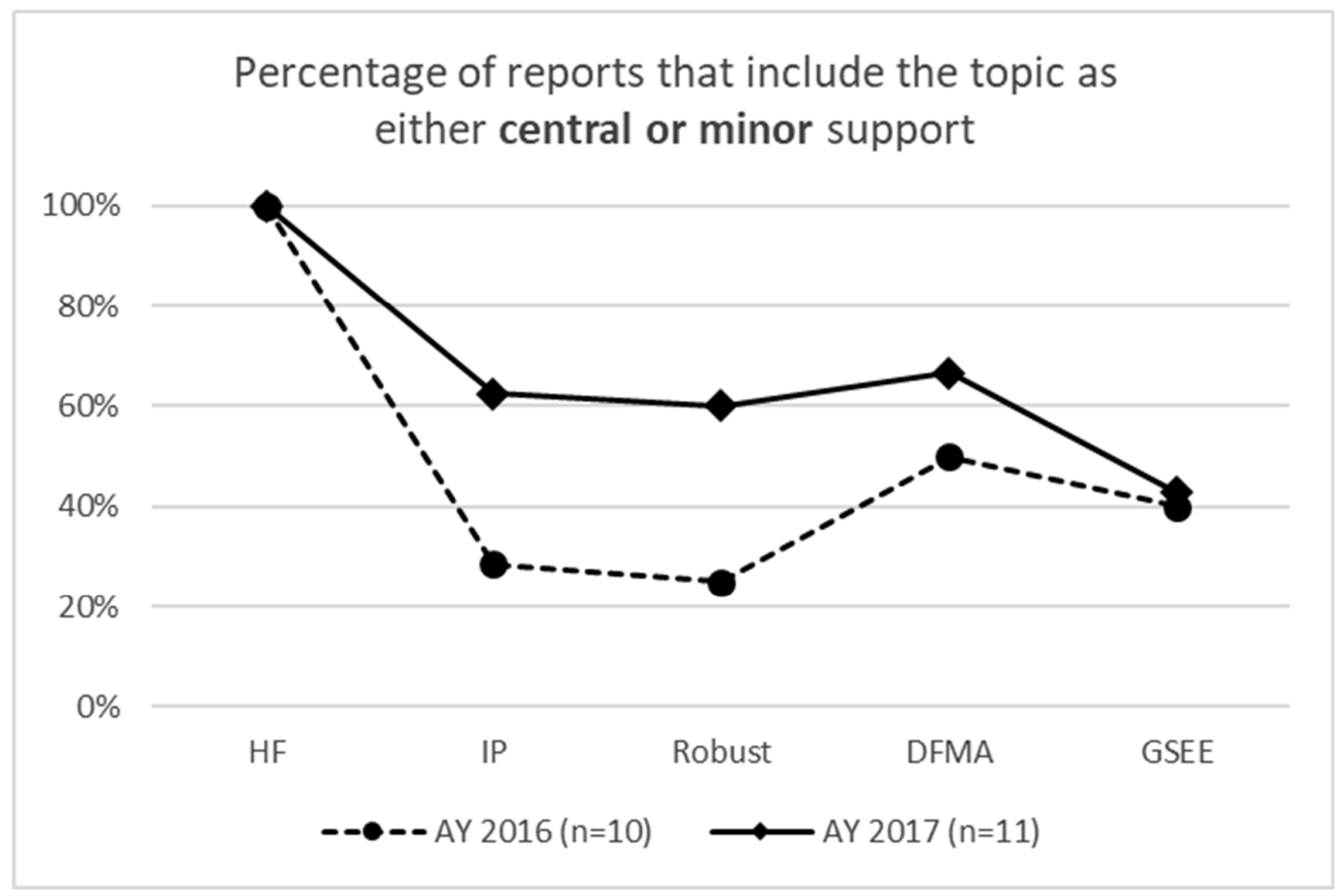

Figure 3. Comparison of how the Application Sessions impacted the inclusion of design topics in the final reports

There was also a noticeable increase in the number of reports that included the design topics as central to their design arguments, as opposed to providing only minor support. This is shown in Figure 4.

We can see the greatest change in the handling of topics that were the newest to the students. More familiar topics, such as Human Factors Engineering, had good representation in both sets of reports. Newer topics, such as IP, Robust Design, and DFMA, had low representation in the earlier reports, and 
stronger representation in the later reports. The GSEE category covers a broad range of potential topics with less-defined targets, making them harder to measure. In addition, some of the GSEE topics assigned for the Application Session had to do with global team collaboration as opposed to the design itself, and would be expected to have less of an impact in the report as design support.

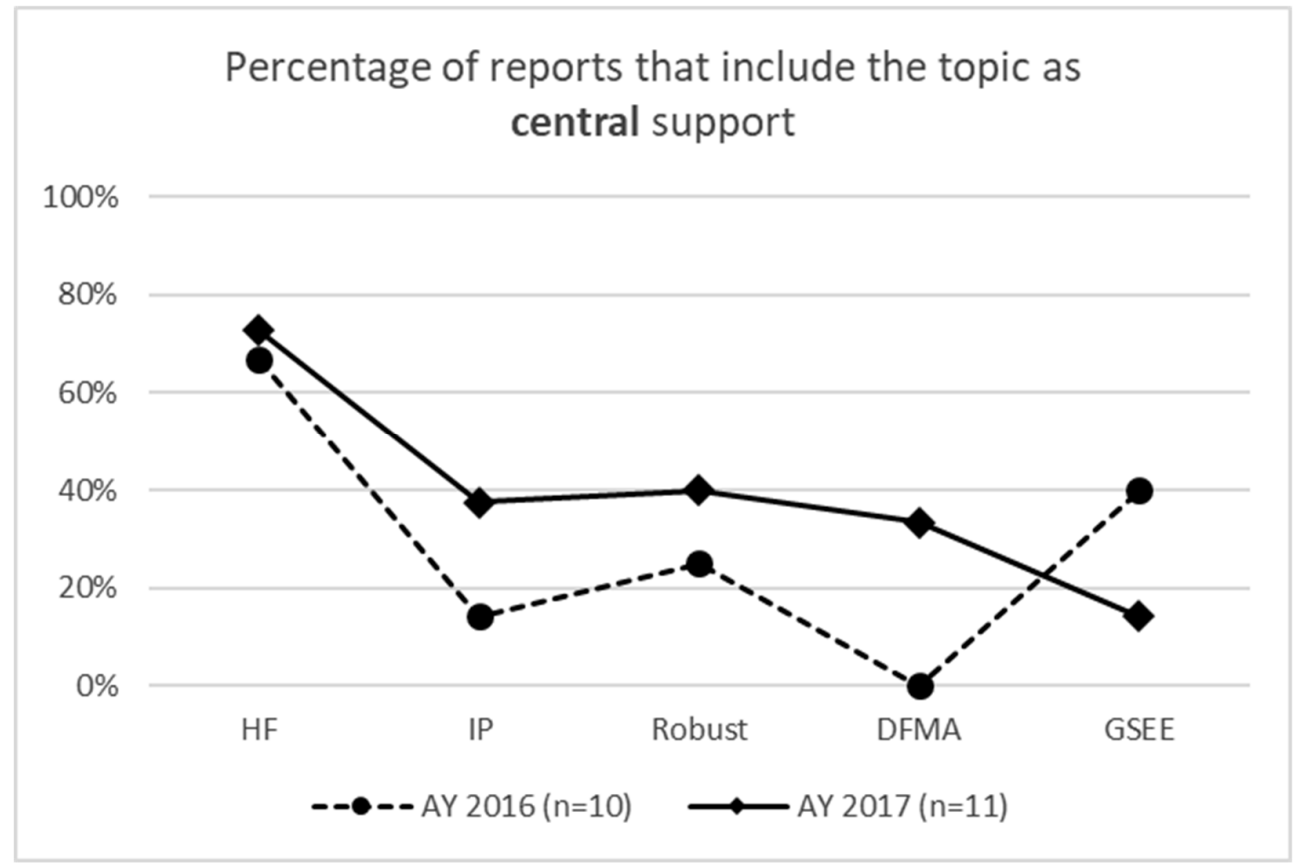

Figure 4. Comparison of how the Application Sessions impacted the degree of support provided by the design topics

Teams that focused on a particular topic for their Application Session did tend to cover that topic in more detail in their reports (64\% of reports addressed their assigned topics within their reports), but not in all cases, and many of the detailed examples came from other teams who had focused on other topics in their Application Sessions. We hypothesize that the Application Sessions raise awareness of the advanced design topics in general, and may also demonstrate the importance placed on the topics by the faculty, leading to greater student engagement.

We also collected feedback from the four teams of students who most recently completed their Application Sessions in the fall of 2017. The two teams assigned to DFMA and Robust design, respectively, both noted that the assignment forced them to look at the chapter in the textbook more critically when considering how to apply it to their project. These teams also noted that it helped them to pay more attention later in the course when there were guest lecturers for each of those topics. The team assigned to DFMA commented, "It helped us evaluate the feasibility of our concepts. We used DFMA principles as criteria to eliminate concepts. We probably would have done this anyway, but it would have been less explicit. This gave us a better way to describe it."

The other two teams from fall of 2017 were assigned topics in Human Factors Engineering and in Client Management. These teams found the assignment less useful, and felt the amount of preparation time burdensome. Both teams did, however, appreciate the feedback and suggestions they received from the other teams.

Students noted that they were able to use some of the slides in a later presentation, and that presenting for the Application Session helped them practice presenting technical concepts. It also helped them relate to the other projects in the class. One student said, "It gave me another level of clarity of what [the other teams] were working on, which [will help] me to give them better feedback later on."

Several students said they would have valued more class discussion time, particularly about how to apply the topics to the different projects. This could be a good mechanism to build further understanding 
of the concepts, and address another student observation that it was difficult to pay attention to all of the presentations.

\section{Conclusions and next steps}

The Application Session allows us to combine three important elements:

- Giving teams responsibility for presenting the topic to the class, and applying it to their projects

- Encouraging active feedback from audience

- Building connections to other projects

All three elements help students focus on evaluating how the topics apply to their project. This is more effective than lectures, activities, or assignments alone. We can see from the increased topic detail in the reports and the student feedback that students are learning more about the advanced design topics. They demonstrate a higher awareness of the significance of the topics and they present their own work in context. A side benefit is that they have more practice in presenting and giving each other feedback. In addition, the exercise in applying their topic to the other projects, as well as exchanging feedback between teams, fosters a community of design in the classroom. This is in contrast to the approach observed by Miller and Summers (2013) who believed that insulating the teams fostered a healthy sense of competition, but is supported by Smith et al. (2005).

To continue to build on this approach, we will explore ways to incorporate more interaction or discussion between the teams during the Application Session, as well as hold the teams more accountable for the material following that session. For example, we could add a metric to their mid-term progress assessment that specifically measures how much they advanced the application of their assigned topic to their project work. We could also require specific follow-up in their mid-term presentations. This would encourage the teams to do more development, and it would also bring the topic to the minds of the other teams one more time.

\section{References}

Davis, D.C., Gentili, K.L., Trevisan, M.S. and Calkins, D.E. (2002), “Engineering Design Assessment Processes and Scoring Scales for Program Improvement and Accountability”, Journal of Engineering Education, Vol. 91 No. 2, pp. 211-221. https://doi.org/10.1002/j.2168-9830.2002.tb00694.x

Dutson, A.J., Todd, R.H., Magleby, S.P. and Sorensen, C.D. (1997), “A Review of Literature on Teaching Engineering Design Through Project-Oriented Capstone Courses”, Journal of Engineering Education, Vol. 86 No. 1, pp. 17-28. https://doi.org/10.1002/j.2168-9830.1997.tb00260.x

Dym, C.L. (2013), Engineering Design: A Project-Based Introduction, 4th ed., Wiley, New York.

Grant, P., Macpherson, D.E., Harrison, D.G., Brunson, K.M., Hyde, R. and Williams, D. (2010), "Teaching integrated system design with interdisciplinary group design exercises”, Engineering Education, Vol. 5 No. 1, pp. 30-41. https://doi.org/10.11120/ened.2010.05010030

Gruenther, K., Bailey, R., Wilson, J., Plucker, C. and Hashmi, H. (2009), "The influence of prior industry experience and multidisciplinary teamwork on student design learning in a capstone design course", Design Studies, Vol. 30 No. 6, pp. 721-736. https://doi.org/10.1016/j.destud.2009.06.001

Miller, W.S. and Summers, J.D. (2013), "Investigating the use of design methods by capstone design students at Clemson University”, International Journal of Technology and Design Education, Vol. 23 No. 4, pp. 10791091. https://doi.org/10.1007/s10798-012-9227-3

Paretti, M.C. (2008), "Teaching Communication in Capstone Design: The Role of the Instructor in Situated Learning”, Journal of Engineering Education, Vol. 97 No. 4, pp. 491-503. https://doi.org/10.1002/j.21689830.2008.tb00995.x

Scott Stanford M., Benson L.C., Alluri P., Martin W.D., Klotz L.E. et al. (2013), "Evaluating Student and Faculty Outcomes for a Real-World Capstone Project with Sustainability Considerations", Journal of Professional Issues in Engineering Education and Practice, Vol. 139 No. 2, pp. $123-133$. https://doi.org/10.1061/(ASCE)EI.1943-5541.0000141 
Shuman, L.J., Besterfield-Sacre, M. and McGourty, J. (2005), “The ABET 'Professional Skills' — Can They Be Taught? Can They Be Assessed?”, Journal of Engineering Education, Vol. 94 No. 1, pp. 41-55. https://doi.org/10.1002/j.2168-9830.2005.tb00828.x

Smith, K.A., Sheppard, S.D., Johnson, D.W. and Johnson, R.T. (2005), "Pedagogies of Engagement: ClassroomBased Practices", Journal of Engineering Education, Vol. 94 No. 1, pp. 87-101. https://doi.org/10.1002/j.2168-9830.2005.tb00831.x

Ulrich, K. and Eppinger, S. (2015), Product Design and Development, 6th ed., McGraw-Hill Education, New York.

Stacy Benjamin, Director, Segal Design Certificate Northwestern University, Segal Design Institute

2133 Sheridan Road, 60208 Evanston, United States

Email: sbenjamin@northwestern.edu 